\title{
Cancro do Colo do Útero: o que sabem as jovens?
}

Catarina Ferreira*, Ana Andreia Matos`, Barros Oliveira*, Joana Bettencourt*

\section{RESUMO}

Objetivos: Avaliar conhecimentos e fontes de informação sobre cancro do colo do útero (CCU), nas jovens com idade igual ou superior a 15 anos, que frequentam as escolas da freguesia de Paço de Arcos.

Tipo de estudo: Estudo observacional, transversal e analítico.

Local: Escola Secundária Luís de Freitas Branco e Escola Básica Joaquim Barros - Paço de Arcos.

População: Alunas com idade igual ou superior a 15 anos que frequentam as escolas da Freguesia de Paço de Arcos, no ano letivo 2010/2011.

Métodos: Dados obtidos por questionário anónimo, com análise das variáveis: idade, ano escolar e conhecimentos sobre CCU [etiologia, sintomatologia, diagnóstico, prognóstico, fatores de risco (FR) e formas de prevenção (FP)].

Resultados: Amostra de 370 jovens, com média de idades de 16,8 anos e de escolaridade o $10 .^{\circ}$ ano. Os meios de comunicação social foram a principal fonte de informação (69,7\%). A vacina foi considerada $100 \%$ eficaz por $18,9 \%$ das jovens. 0 principal FR identificado $(79,2 \%)$ foi «relações sexuais sem preservativo» e a FP $(98,1 \%)$ foi a vacina contra o Vírus do Papiloma Humano (HPV). Em média, cada jovem identificou apenas um terço dos FR e cerca de metade das FP apresentadas. Não se verificou qualquer relação entre idade, ano escolar, e/ou frequência de uma consulta na Unidade de Saúde Familiar (USF) ou Unidade de Cuidados de Saúde Personalizados (UCSP) no último ano e os conhecimentos demonstrados.

Conclusões: O CCU é uma doença com elevada morbilidade e mortalidade, com medidas preventivas conhecidas e acessíveis. Os conhecimentos demonstrados pela amostra do estudo são superiores aos referidos na bibliografia internacional consultada. Contudo, este estudo permitiu aos autores identificar algumas lacunas de conhecimento, que podem ser alvo de estratégias de promoção de saúde. Os meios de comunicação social, enquanto principal fonte de informação, podem, a par dos profissionais de saúde, ser um veículo importante na transmissão de conhecimentos.

Palavras-chave: Conhecimentos; Cancro do Colo do Útero; Jovens do Sexo Feminino.

\section{INTRODUÇÃO}

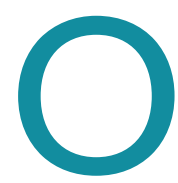

CCU é uma das principais causas de morte por neoplasia, nas mulheres, em todo o mundo. É hoje aceite que a principal etiologia do CCU é a infeção persistente pelas estirpes oncogénicas do HPV. ${ }^{1}$ A adolescência constitui um período de maior risco de infeção por este vírus e consequente displasia cervical. ${ }^{2,3}$ Na maioria dos casos, a infeção por HPV é eficazmente eliminada; no entanto, pode persistir e originar lesões pré-cancerígenas e cancerígenas. ${ }^{4,5}$ Segundo a Organização Mundial de Saúde, os principais fatores de risco para CCU são infeção por HPV, início precoce de atividade sexual, relações sexuais sem preservativo, grande número de parceiros sexuais,

${ }^{\dagger}$ Assistente de Medicina Geral e Familiar, USF Jardim dos Plátanos, Oeiras.

* Internos do $3 .^{\circ}$ ano Medicina Geral e Familiar, USF Delta, Oeiras. outras infeções sexualmente transmissíveis [ex.: infeção pelo Vírus da Imunodeficiência Humana (HIV)], outras condições associadas a diminuição da imunidade, tabagismo e uso prolongado de contracetivo oral. Os principais fatores protetores incluem uso de preservativo, número reduzido de parceiros sexuais, início tardio de atividade sexual, vacina contra o HPV e realização regular de exame ginecológico, incluindo citologia cervical. A história natural da doença, desde a infeção até ao CCU, é bem conhecida e a sua evolução lenta, ${ }^{6}$ pelo que o programa de rastreio direcionado às mulheres entre os 25-64 anos é eficaz. ${ }^{7}$ Em Portugal, existem cerca de 1000 novos casos de CCU todos os anos, ${ }^{8}$ o que nos alerta para a importância deste rastreio na nossa população.

Tendo em conta que o conhecimento sobre CCU é um fator essencial na sua prevenção, consideramos que a recente introdução da vacina no Plano Nacional deVa- 
cinação poderia ser uma oportunidade de promoção e educação para a saúde nesta área.

Este estudo teve como objetivo determinar os conhecimentos sobre o CCU, os FR e as FP.

\section{MÉTODOS}

Tratou-se de um estudo observacional, transversal e analítico, realizado durante o mês de maio de 2011, que teve por objetivo determinar os conhecimentos das jovens sobre CCU.

A população do estudo foi composta por jovens do sexo feminino com idade igual ou superior a 15 anos (tendo em conta o ano de aplicação do questionário), a frequentar o ensino obrigatório público na freguesia de Paço de Arcos - Escola Secundária Luís de Freitas Branco e Escola Básica Joaquim Barros no ano 2010/2011.

A avaliação dos dados demográficos e dos conhecimentos foi feita através da aplicação de um questionário anónimo (em anexo), elaborado pelos autores tendo por base outros estudos que apresentavam objetivos semelhantes. ${ }^{9-16}$ Apesar de não validado, o questionário foi submetido a um teste piloto com 20 jovens de características demográficas semelhantes às da população alvo, que frequentavam uma escola pública do mesmo concelho, mas de uma freguesia diferente, não tendo sido efetuadas alterações ao questionário.

$\mathrm{O}$ estudo foi integrado no âmbito da saúde escolar na Escola Luís de Freitas Branco, com existência prévia de consentimento informado por parte dos encarregados de educação das jovens menores, para os projetos aplicados neste contexto. Na Escola Joaquim Barros também se obteve o consentimento informado por parte dos encarregados de educação, para este projeto específico, antes da aplicação do questionário.

O questionário foi aplicado a uma amostra de conveniência da população em estudo, constituída por jovens do sexo feminino, nascidas até 31 de dezembro de 1996, que aceitaram e/ou foram autorizadas a responder ao questionário e estavam presentes no período de obtenção de dados, sendo estes os critérios de inclusão.

As variáveis medidas foram idade, ano escolar, frequência de consulta na USF ou UCSP no último ano, fontes de informação e conhecimentos sobre CCU, nomeadamente quanto à sua etiologia, sintomatologia, meios de diagnóstico, FR e FP. (Figura 1)

Os dados recolhidos foram registados e analisados através das aplicações Microsoft Excel® e SPSS ${ }^{\circledR}$ 16.0. Inicialmente, foi utilizada uma análise descritiva para caracterização da amostra estudada e das opções correta e incorretamente assinaladas relativamente às variáveis que permitiam avaliar os conhecimentos. Através do coeficiente de correlação de Pearson foi efetuada a comparação entre a percentagem média de respostas corretas, relativamente aos FR e às FP, com as variáveis idade e ano escolar. Para avaliar a relação entre o número médio de respostas corretas (FR e FP) e a ida a uma consulta na USF ou UCSP no último ano aplicou-se o teste de Mann-Whitney.

\section{RESULTADOS}

Da população, constituída por 519 jovens, obteve-se uma amostra de 370 jovens $(71,29 \%)$ com média de idades de 16,8 anos (mínimo de 14 e máximo de 23 anos) e de escolaridade o $10 .^{\circ}$ ano (mínimo o $7 .^{\circ}$ e máximo o $12 .^{\circ}$ ano). Destas, $344(92,97 \%)$ afirmaram ter ido a uma consulta na USF ou UCSP no último ano. (Figura 2)

Os meios de comunicação social foram a principal fonte de informação selecionada $(69,7 \%)$, seguida dos profissionais de saúde (55,9\%). (Figura 3)

Relativamente ao aparelho afetado pelo CCU, 97,8\% das jovens identificaram o aparelho genital feminino. A maioria das jovens identificou corretamente o HPV como agente etiológico (69,5\%), referiu que o CCU pode ser assintomático $(78,4 \%)$ (Figura 4), identificou a citologia como método diagnóstico $(78,1 \%)$ (Figura 5) e o CCU como uma doença que se pode prevenir e tratar desde que diagnosticado precocemente $(73,8 \%$ e $63,8 \%$, respetivamente); uma percentagem considerável de jovens referiu que a vacina é $100 \%$ eficaz (18,9\%) (Figura 6).

O FR mais assinalado foi «relações sexuais sem preservativo", todos os restantes fatores de risco foram identificados por metade ou menos das jovens. O segundo fator mais escolhido foi a falta de higiene feminina (Figura 7). Dos FR assinalados, $76 \%$ eram verdadeiros e $24 \%$ falsos, o que corresponde a um ratio de $3 / 1$ (três respostas certas por cada resposta errada).

De acordo com os dados anteriores, a realização de higiene feminina adequada foi identificada como forma de prevenção por mais de metade das jovens (Figura 8). Das FP assinaladas, $80 \%$ eram verdadeiras e $20 \%$ falsas, o que corresponde a um ratio de 4/1 (quatro respostas certas por cada resposta errada). 


\begin{tabular}{|c|c|c|c|c|c|c|}
\hline N. ${ }^{\circ}$ & Nome & \multicolumn{2}{|c|}{ Definição conceptual } & Definição Operacional & Tipo & $\begin{array}{l}\text { Resultado } \\
\text { esperado }\end{array}$ \\
\hline 1 & Idade & \multicolumn{2}{|r|}{ Idade } & $\begin{array}{c}\text { Número de anos de vida à } \\
\text { data de aplicação do } \\
\text { questionário }\end{array}$ & $\begin{array}{l}\text { Quantitativa } \\
\text { discreta }\end{array}$ & Média e moda \\
\hline 2 & Ano escolar & \multicolumn{2}{|c|}{ Ano escolar } & $\begin{array}{c}\text { Ano lectivo frequentado } \\
\text { na data de aplicação } \\
\text { do questionário }\end{array}$ & $\begin{array}{l}\text { Quantitativa } \\
\text { discreta }\end{array}$ & Média e moda \\
\hline 3 & MF & \multicolumn{2}{|c|}{ Presença de MF atribuído } & $\begin{array}{l}\text { Pertencer à lista de utentes } \\
\text { de um MF }\end{array}$ & $\begin{array}{l}\text { Qualitativa } \\
\text { nominal }\end{array}$ & Percentagem \\
\hline 4 & Consulta & \multicolumn{2}{|c|}{$\begin{array}{l}\text { Frequência de consulta na USF ou UCSP } \\
\text { no último ano }\end{array}$} & $\begin{array}{l}\text { Ida a qualquer tipo de } \\
\text { consulta na USF ou UCSP no } \\
\text { ano anterior à data de } \\
\text { aplicação do questionário }\end{array}$ & $\begin{array}{l}\text { Qualitativa } \\
\text { nominal }\end{array}$ & Percentagem \\
\hline \multirow{6}{*}{5} & \multirow{6}{*}{$\begin{array}{l}\text { Fontes de } \\
\text { informação }\end{array}$} & \multirow{6}{*}{$\begin{array}{l}\text { Fontes de } \\
\text { informação }\end{array}$} & Comunicação social & \multirow{6}{*}{$\begin{array}{l}\text { Fontes a partir das quais } \\
\text { a amostra obteve } \\
\text { informações/conhecimentos } \\
\text { sobre CCU }\end{array}$} & \multirow{6}{*}{$\begin{array}{l}\text { Qualitativas } \\
\text { nominais }\end{array}$} & \multirow{6}{*}{ Percentagem } \\
\hline & & & Profissionais de saúde & & & \\
\hline & & & Família & & & \\
\hline & & & Escola & & & \\
\hline & & & Amigos & & & \\
\hline & & & Outra & & & \\
\hline \multirow{7}{*}{6} & \multirow{7}{*}{ Conhecimentos } & \multirow{7}{*}{$\begin{array}{l}\text { Conhecimentos } \\
\text { sobre CCU }\end{array}$} & $\begin{array}{l}\text { Aparelho de órgãos } \\
\text { afetado }\end{array}$ & \multirow{7}{*}{$\begin{array}{c}\text { Conhecimentos } \\
\text { demonstrados pela amostra } \\
\text { em relação ao CCU, tendo } \\
\text { em conta o aparelho de } \\
\text { órgãos afetado, a etiologia, a } \\
\text { sintomatologia, o } \\
\text { diagnóstico, o prognóstico, } \\
\text { os fatores de risco e as } \\
\text { formas de prevenção }\end{array}$} & \multirow{7}{*}{$\begin{array}{l}\text { Qualitativas } \\
\text { nominais }\end{array}$} & \multirow{7}{*}{ Percentagem } \\
\hline & & & Etiologia & & & \\
\hline & & & Sintomatologia & & & \\
\hline & & & Diagnóstico & & & \\
\hline & & & Prognóstico & & & \\
\hline & & & Fatores de risco & & & \\
\hline & & & Formas de prevenção & & & \\
\hline
\end{tabular}

Figura 1. Definição operacional das variáveis.

Em média, cada jovem identificou apenas um terço dos FR e cerca de metade das FP apresentadas.

Não se verificou qualquer relação entre os FR e as FP identificados e a idade (coeficiente de correlação de Pearson $\rho=0,084$ para os FR e $\rho=0,148$ para as FP) e/ou ano escolar (coeficiente de correlação de Pearson $\rho=0,005$ para os FR e $\rho=0,030$ para as FP) e/ou existência de uma consulta na USF ou UCSP no último ano (teste de Mann-Whitney $\mathrm{p}=0,402$ para os FR e $\mathrm{p}=0.833$ para as FP), o que está de acordo com os resultados obtidos nas fontes de informação.

\section{DISCUSSÃO}

Este trabalho permitiu melhorar a perceção dos conhecimentos sobre CCU das jovens de duas escolas da área de abrangência da USF dos autores, na faixa etária onde é maior o risco de infeção pelo seu principal agente etiológico. ${ }^{9,17,18}$

Salienta-se o fato de $100 \%$ da amostra referir já ter ouvido falar do CCU, o que está de acordo com outro estudo realizado em Portugal. ${ }^{15}$ No entanto, estes valores variam bastante em vários estudos internacionais, desde $15 \%$ a $85 \% .^{9-13,16}$ 


\begin{tabular}{|c|c|}
\hline Idade & $n(\%)$ \\
\hline 14 & $31(8,38)$ \\
\hline 15 & $67(18,11)$ \\
\hline 16 & $74(20,00)$ \\
\hline 17 & $72(19,46)$ \\
\hline 18 & $70(18,92)$ \\
\hline 19 & $33(8,92)$ \\
\hline 20 & $16(4,32)$ \\
\hline 21 & $4(1,08)$ \\
\hline 22 & $2(0,54)$ \\
\hline 23 & $1(0,27)$ \\
\hline Ano Escolar & $n(\%)$ \\
\hline 7 & $8(2,16)$ \\
\hline 8 & $24(6,49)$ \\
\hline 9 & $62(16,76)$ \\
\hline 10 & $89(24,05)$ \\
\hline 11 & $101(27,3)$ \\
\hline 12 & $86(23,24)$ \\
\hline $\begin{array}{l}\text { Médico de } \\
\text { Familia atribuído }\end{array}$ & n (\%) \\
\hline $\mathrm{s}$ & $319(86,22)$ \\
\hline $\mathrm{N}$ & $20(5,41)$ \\
\hline NS/NR & $31(8,38)$ \\
\hline $\begin{array}{l}\text { Consulta na } \\
\text { USF/UCSP no } \\
\text { último ano }\end{array}$ & n (\%) \\
\hline $\mathrm{s}$ & $346(93,51)$ \\
\hline $\mathrm{N}$ & $23(6,22)$ \\
\hline NS/NR & $1(0,27)$ \\
\hline
\end{tabular}

Figura 2. Caracterização da amostra $(S=\operatorname{sim} ; \mathrm{N}=$ não; $\mathrm{NS} / \mathrm{NR}=$ não sabe/não responde)

Os meios de comunicação social constituem o principal vetor de informação assinalado, o que pode explicar a inexistência de relação entre os conhecimentos demonstrados e a frequência de uma consulta na USF ou UCSP no último ano. Isto traduz uma necessidade de melhoria na transmissão desta informação pelos profissionais de saúde aos utentes e alerta para a importância da qualidade das informações de promoção

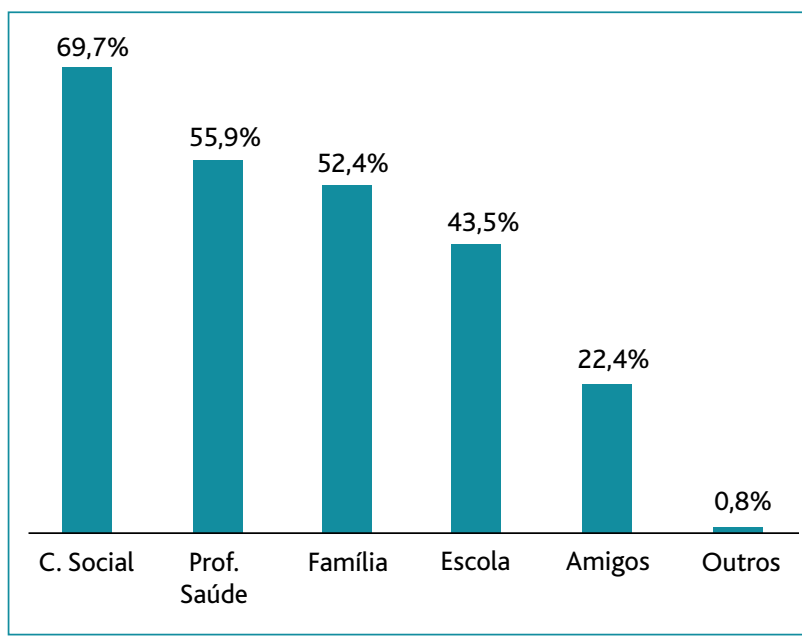

Figura 3. Fontes de informação sobre CCU)

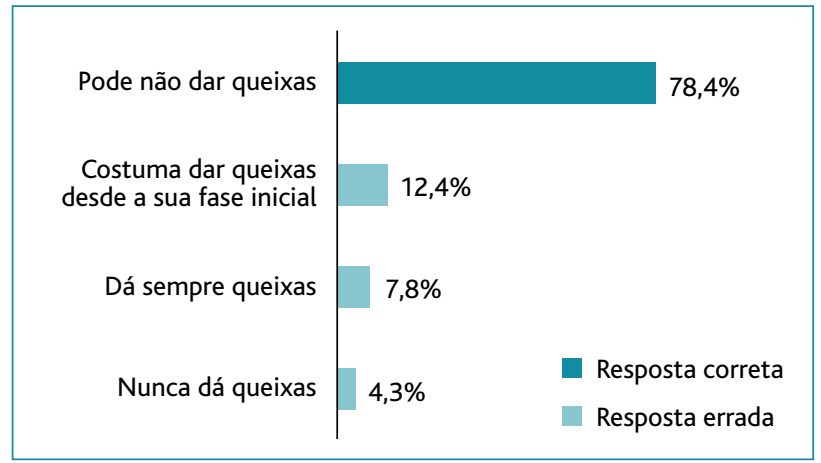

Figura 4. Respostas obtidas relativamente à sintomatologia do CCU

de saúde nos meios de comunicação social. Estes dados são mais uma vez coincidentes com aqueles encontrados noutro estudo português. ${ }^{15}$

A citologia do colo do útero foi identificada corretamente, pela maioria das jovens $(78,1 \%)$ como o meio de diagnóstico do CCU, resultado este semelhante ao encontrado num estudo nacional ${ }^{15} \mathrm{e}$ muito superior ao de um estudo internacional $(1,3 \%) .{ }^{19}$ Contudo, a percentagem de jovens que assinalou as restantes opções («radiografia do colo do útero», «análises de sangue» e «análises de urina») não é desprezável, salientando as dúvidas existentes nesta área.

A maioria das jovens considera que o CCU é uma doença prevenível e com potencial de cura quando detetada precocemente, o que poderá constituir um fator preditor de adesão ao rastreio. No entanto, uma per- 


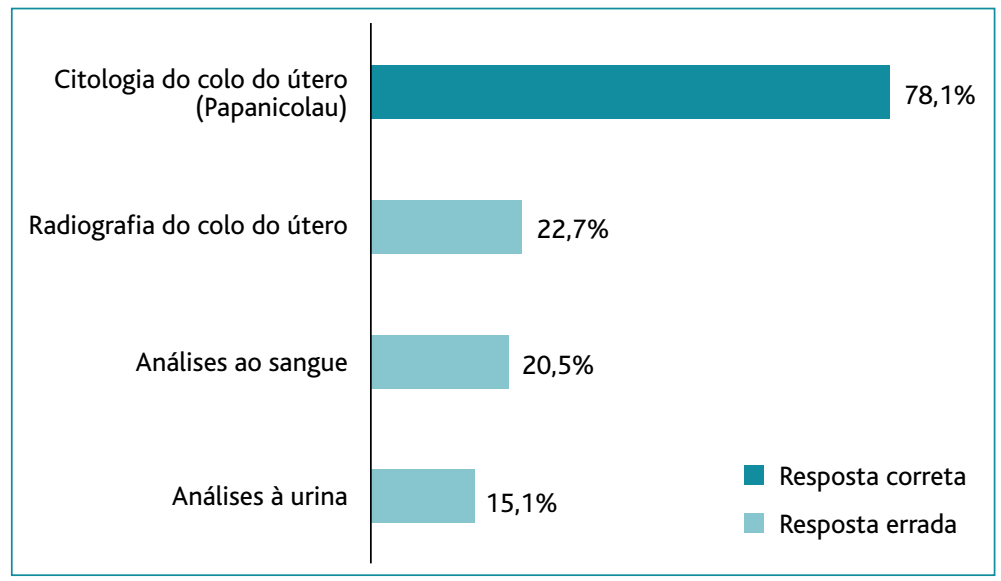

Figura 5. Respostas obtidas relativamente ao diagnóstico do CCU

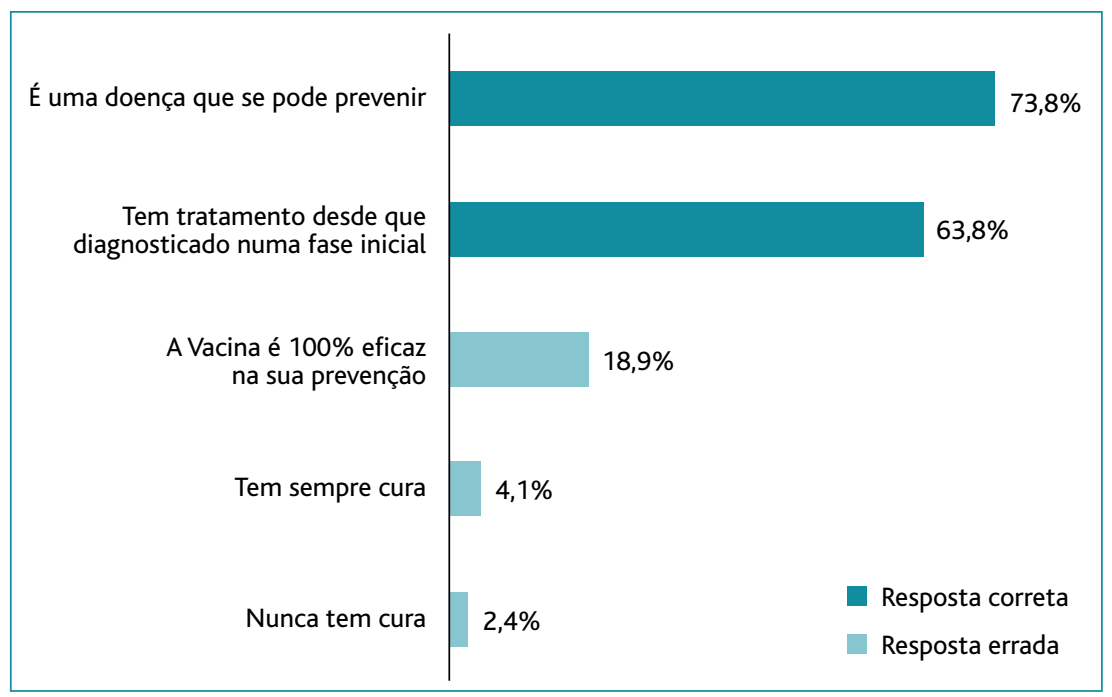

Figura 6. Respostas obtidas relativamente à prevenção e tratamento do CCU

vo» $[3 \%],{ }^{13}$ «Grande número de parceiros sexuais» [3\%, 14\% e 65\%], , ${ }^{10,13,14}$ «Ter outras infeções sexualmente transmitidas» [7\% e $87 \%$ ], ${ }^{13,14}$ «Início precoce de atividade sexual» $[7 \%$ e $57 \%],{ }^{13,14}$ «Tabagismo» [7\%]. ${ }^{13}$

A falta de higiene feminina" foi o mito mais vezes identificado no nosso trabalho $(55,7 \%)$, apesar de este valor ser inferior ao encontrado num estudo internacional $[87 \%]{ }^{14}$

De referir que os estudos internacionais encontrados foram realizados em países em desenvolvimento ou em zonas sócio-culturais/económicas de risco de países desenvolvidos, nos quais os níveis de conhecimento global são expectavelmente mais baixos do que nos países «ditos desenvolvidos». Neste sentido, considerando a nossa realidade, era de esperar que as jovens em estudo apresentassem um nível de conhecimentos superior ao obtido na bibliografia consultada, o que se verificou. No entanto, estudos demonstram não existir uma associação direta entre nível de conhecimentos e atitudes, ${ }^{16}$ dado existirem vários fatores que podem influenciar a aquisição de comportamentos saudáveis (ex.: perceção de risco, influência social e autoeficácia). ${ }^{11}$ Deste modo, parece ser fundamental aliar as duas estratégias: por um lado, avaliar os co-

centagem significativa considera que a vacina é $100 \%$ eficaz, o que deverá ser prontamente esclarecido, de forma a evitar uma falsa sensação de segurança após a vacinação, com consequente desvalorização da importância do exame ginecológico.

Relativamente aos fatores de risco e formas de prevenção, as percentagens de respostas corretamente identificadas foram semelhantes às apresentadas no estudo nacional encontrado. ${ }^{15}$ A maioria dos estudos internacionais não apresenta estes dados quantificados, referindo, no entanto um baixo nível de conhecimento geral. Dos estudos que apresentam quantificação, os valores são díspares: «Relações sexuais sem preservati- nhecimentos da população alvo, de modo a identificar as lacunas que deverão ser colmatadas e, por outro, identificar e combater as barreiras que possam impedir a aplicação dos conhecimentos.

Como limites do estudo, salientamos que a população abrangida não foi padronizada, pelo que os dados não poderão ser extrapoláveis para a população portuguesa. A amostra utilizada é uma amostra de conveniência, que corresponde a 73,4\% da população (população: 504; amostra: 370). Por outro lado, o questionário utilizado, apesar de ter sido sujeito a um teste piloto, não foi validado para a população portuguesa e algumas das hipóteses de resposta poderiam suscitar di- 
ferentes interpretações. O nível de conhecimento foi aferido pela percentagem de respostas corretas e incorretas, em comparação com os estudos encontrados, sem uso de um instrumento de quantificação do conhecimento.

Apesar das limitações referidas, este estudo permitiu-nos avaliar uma parte da população a quem prestamos diariamente cuidados de saúde, como médicos de família, alertando-nos para possíveis lacunas que necessitem de ser colmatadas, por forma a aumentar a nossa eficácia na prevenção da doença e promoção da saúde.

Seria desejável a realização de outros estudos, com uma amostra representativa da população portuguesa e aplicação de uma grelha de avaliação de conhecimentos, assim como avaliar a associação entre nível de conhecimentos e atitudes, permitindo uma intervenção mais eficaz por parte dos profissionais de saúde.

\section{REFERÊNCIAS BIBLIOGRÁFICAS}

1. Walboomers JM, Jacobs MV, Manos MM, Bosch FX, Kummer JA, Shah KV, et al. Human papillomavirus is a necessary cause of invasive cervical cancer worldwide. J Pathol 1999 Sep; 189 (1): 12-9.

2. Powell J, Strauss S, Gray J, Wojnarowska F. Genital carriage of human papillomavirus (HPV) DNA in prepubertal girls with and without vulval disease. Pediatr Dermatol 2003 May-Jun; 20 (3): 191-4.

3. Cubie HA, Plumstead M, Zhang W, de Jesus $O$,

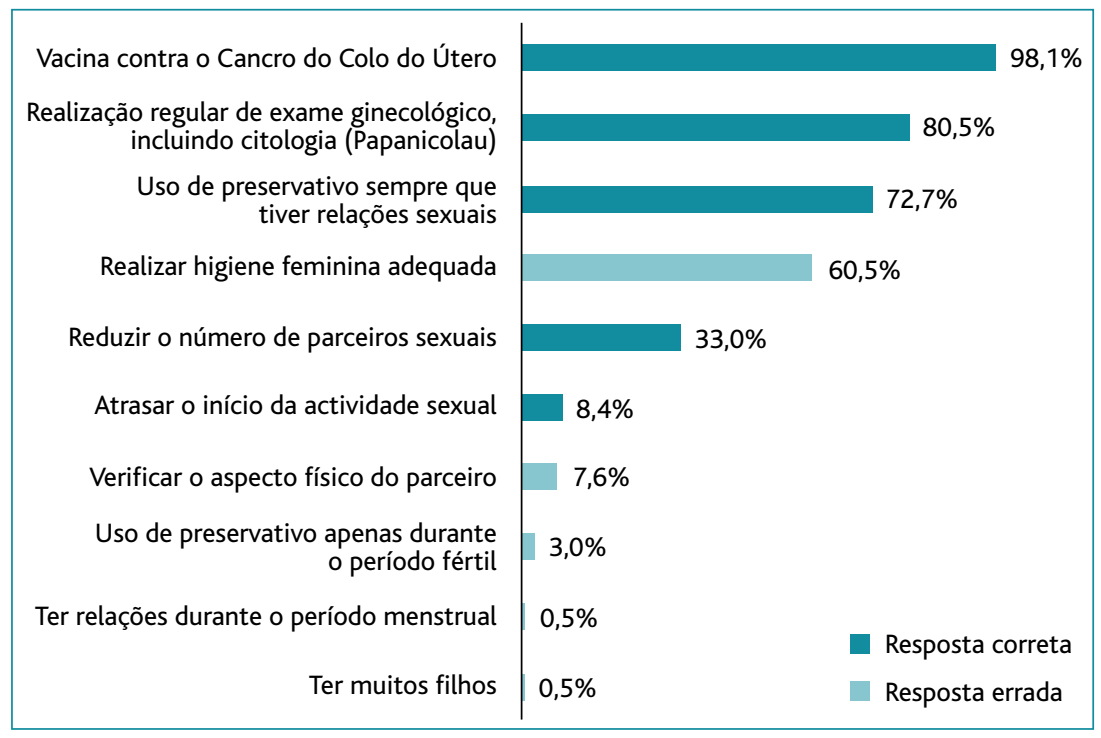

Figura 8. Respostas obtidas relativamente a formas de prevenção do CCU Duncan LA, Stanley MA. Presence of antibodies to human papillomavirus virus-like particles (VLPS) in 11-13 year old schoolgirls. J Med Virol 1998 Nov; 56 (3): 210-6.

4. Baseman JG, Koutsky LA. The epidemiology of human papillomavirus infections. J Clin Virol 2005 Mar; 32 Suppl 1: S16-24.

5. Bosch FX, Burchell AN, Schiffman M, Giuliano AR, de Sanjose S, Bruni

L, et al. Epidemiology and natural history of human papillomavirus infections and type-specific implications in cervical neoplasia. Vaccine 2008 Aug 19; 26 Suppl 10: K1-16.

6. Schiffman M, Castle P, Jeronimo J, Rodriguez AC, Wacholder S. Human papillomavirus and cervical cancer. Lancet 2007 Sep 8; 370 (9590):890-907. 
7. World Health Organization, International Agency for Research on Cancer. IARC Handbooks of Cancer Prevention: Cervix Cancer Screening. Lyon: IARC Press; 2005.

8. Costa C, Garcia AC, Rascoa C, Santana R, Lopes S. Avaliação económica do Gardasil ${ }^{\circledR}$. Lisboa: Escola Nacional de Saúde Pública; 2007.

9. World Health Organization. Comprehensive Cervical Cancer Control: a Guide to Essential Practice. Geneva:WHO; 2006.

10. Saha A, Chaudhury AN, Bhowmik P, Chatterjee R. Awareness of cervical cancer among female student of premier colleges in Kolkata, India. Asian Pac J Cancer Prev 2010; 11 (4): 1085-90.

11. Tiro JA, Meissner HI, Kobrin S, Chollette V. What do women in the U.S. know about human papillomavirus and cervical cancer? Cancer Epidemol Biomarkers Prev 2007 Feb; 16 (2): 288-94.

12. Fotinatos N, Warmington A, Walker T, Pilbeam M. Knowledge and perceptions of cervical cancer and healthcare in Vanuatu. Health Promot Austr 2010 Aug; 21 (2): 127-9.

13. Marlow LA, Walter J, Wardle J. Public awareness that HPV is a risk factor for cervical cancer. Br J Cancer 2007 Sep; 97 (5): 691-4.

14. Do HH, Taylor VM, Burke N, Yasui Y, Schwartz SM, Jacksopn JC. Knowledge about cervical cancer risk factors, traditional health beliefs, and pap testing among Vietnamese American Women. J Immigr Minor Health 2007 Apr; 9 (2): 109-14.

15. Malheiro S. Cancro do colo do útero: conhecimentos e comportamentos. Ponte de Lima: Universidade Fernando Pessoa; 2009.

16. Nnodu O, Erinosho L, Jamda M, Olaniyi O, Adelayde R, Lawson L, et al. Knowledge and attitudes toward cervical cancer and human papilloma- virus: a Nigerian pilot study. Afr J Reprod Health 2010 Mar; 14 (1): 95-108.

17. Hogue ME. Cervical cancer awareness and preventive behavior among female university students in South Africa. Asian Pac J Cancer Prev 2010; 11 (1): 127-30.

18. Francis SA, Nelson J, Liverpool J, Soogun S, Mofammere N, Thorpe RJ Jr. Examining attitudes and knowledge about HPV and cervical cancer risk among female clinic attendees in Johannesburg, South Africa. Vaccine 2010 Nov 23; 28 (50): 8026-32.

19. Mosavel M, El-Shaarawi N. "I have never heard that one": young girls' knowledge and perception of cervical cancer. J Health Commun 2007 Dec; 12 (8): 707-19.

\section{CONFLITOS DE INTERESSE}

Os autores declaram que o estudo não foi financiado e não existirem conflitos de interesse na elaboração deste artigo.

\section{ENDEREÇO PARA CORRESPONDÊNCIA \\ Abílio Tiago Barros Oliveira \\ Avenida António Bernardo Cabral Macedo \\ 2770-219 Paço de Arcos \\ Correio eletrónico: abiliotiago@hotmail.com}

Recebido em 24/10/2013

Aceite para publicação em 22/07/2013

Artigo escrito ao abrigo do novo acordo ortográfico.

\section{ABSTRACT}

\section{CERVICAL CANCER:WHAT DO GIRLS KNOW?}

Objectives: To assess the knowledge and sources of information of young girls on cervical cancer.

Type of study: Cross-sectional study

Location: Paço de Arcos' high school and middle school.

Population: Female students aged 15 years and over attending public schools in Paço de Arcos, Portugal in the academic year 2010-2011.

Methods: Data were obtained in an anonymous questionnaire. Variables studied included age, school year, and knowledge of cervical cancer (including etiology, symptoms, diagnosis, prognosis, risk factors and prevention).

Results: The sample included 370 students, with a mean age of 16,8 years and 10 years of schooling. Communications media were the main source of information (69.7\%). The vaccine was considered $100 \%$ effective by $18,9 \%$ of students. The main risk factor identified was "unprotected sex". The main form of prevention identified was the vaccine against Human Papilloma Virus. Students identified only one third of the risk factors and half of the means prevention. There was no relationship between age, school year, or visiting the health center in the last year and knowledge of cervical cancer.

Conclusions: Cervical cancer is a preventable disease, with high morbidity and mortality worldwide. The level of knowledge found in this study sample was higher than that found in other studies. This study identifies gaps in knowledge that can be a target for health promotion programs. The media and health care professionals can share responsibility in educating the public about cervical cancer.

Keywords: Knowledge; Uterine Cervical Neoplasms; Female Adolescents. 


\section{ANEXO I \\ QUESTIONÁRIO DE CONHECIMENTOS SOBRE CANCRO DO COLO DO ÚTERO}

Data de nascimento:

Ano escolar:

Tem Médico de Família atribuído? Sim

Não

Foi a uma consulta no Centro de Saúde no último ano? Sim

Não

1. Já ouviu falar no Cancro do Colo do Útero?

Sim

Não

Se sim, responda às questões seguintes.

2. Onde obteve informação sobre Cancro do Colo do Útero?

Profissionais de saúde (médico, enfermeiro ou farmacêutico)

Meios de comunicação (televisão, rádio, internet, jornais, revistas, ...)

Familiares

Escola

Amigos

Outro

Qual?

3. Selecione as verdadeiras (pode haver mais do que uma opção verdadeira em cada alínea):

3.1

O Cancro do Colo do Útero é uma doença do Aparelho Gastrointestinal

O Cancro do Colo do Útero é uma doença do Aparelho Genital Feminino

O Cancro do Colo do Útero é uma doença do Aparelho Respiratório

O Cancro do Colo do Útero é uma doença do Aparelho Genital Masculino

3.2

O Cancro do Colo do Útero é causado pelo Vírus Herpes

O Cancro do Colo do Útero é causado pelo Vírus da Imunodeficiência Humano (HIV)

O Cancro do Colo do Útero é causado pelo Vírus do Papiloma Humano (HPV)

O Cancro do Colo do Útero é causado por uma bactéria

\section{3}

O Cancro do Colo do Útero costuma dar queixas desde a sua fase inicial

O Cancro do Colo do Útero pode não dar queixas

O Cancro do Colo do Útero dá sempre queixas

O Cancro do Colo do Útero nunca dá queixas
3.4

O diagnóstico pode fazer-se por análises ao sangue

O diagnóstico pode fazer-se por análises à urina

O diagnóstico pode fazer-se por citologia do colo do útero

(Papanicolau)

O diagnóstico pode fazer-se por radiografia do colo do útero

3.5

O Cancro do Colo do Útero é uma doença que se pode prevenir

A vacina contra o Cancro do Colo do Útero é $100 \%$ eficaz na prevenção da doença

O Cancro do Colo do Útero tem tratamento desde que seja diagnosticado numa fase inicial

O Cancro do Colo do Útero tem sempre cura

O Cancro do Colo do Útero nunca tem cura

4. Das seguintes frases selecione as verdadeiras sobre fatores de risco para Cancro do Colo do Útero

Tabagismo

Relações sexuais sem preservativo

Grande número de parceiros sexuais

Falta de higiene feminina

Início precoce de atividade sexual

Idade jovem

Condições associadas a diminuição de imunidade __

Ter muitos filhos

Ter outras infeções transmitidas sexualmente (por exemplo HIV)

Uso prolongado de pílula

Ter um Dispositivo Intra-Uterino (DIU)

Uso de tampões

Ter relações durante o período menstrual

5. Das seguintes frases selecione as verdadeiras sobre formas de prevenção de Cancro do Colo do Útero?

Uso de preservativo sempre que tiver relações sexuais

Vacina contra o Cancro do Colo do Útero

Reduzir o número de parceiros sexuais

Realizar higiene feminina adequada

Atrasar o início da atividade sexual

Uso de preservativo apenas durante o período fértil

Realização regular de exame ginecológico, incluindo citologia (Papanicolau)

Verificar o aspeto físico do parceiro

Ter relações durante o período menstrual

Ter vários parceiros sexuais

Ter muitos filhos 
estudosoriginais

Comentários: 